Document downloaded from:

http://hdl.handle.net/10251/176298

This paper must be cited as:

Gabirondo, E.; Sangroniz, A.; Etxeberria, A.; Torres-Giner, S.; Sardon, H. (2020). Poly(hydroxy acids) derived from the self-condensation of hydroxy acids: from polymerization to end-of-life options. Polymer Chemistry. 11(30):4861-4874. https://doi.org/10.1039/D0PY00088D

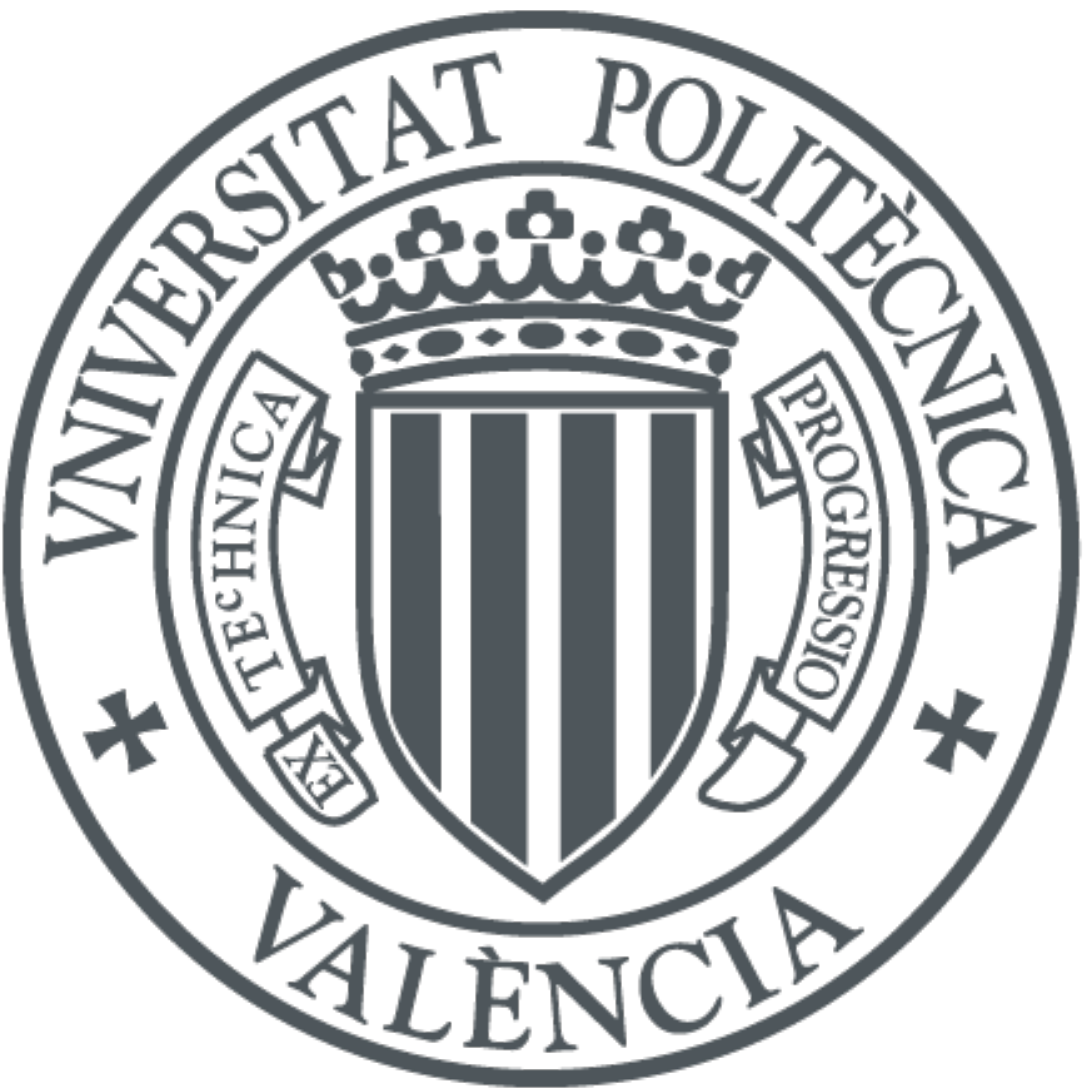

The final publication is available at

https://doi.org/10.1039/D0PY00088D

Copyright Royal Society of Chemistry

Additional Information 


\title{
Poly(hydroxy acids) derived from the self-condensation of hydroxy acids: from polymerization to end-of-life options
}

Received 00th January 20xx, Accepted 00th January 20xx DOI: $10.1039 / \times 0 \times x 00000 x$

\author{
Elena Gabirondo, ${ }^{a}$ Ainara Sangroniz, ${ }^{a}$ Agustin Etxeberria, ${ }^{a}$ Sergio Torres-Giner, ${ }^{* b}$ and Haritz Sardon*a
}

\begin{abstract}
Poly(hydroxy acids) have gained an increasing attention in the search of novel sustainable materials to replace petrochemical polymers in packaging applications. Poly(hydroxy acids) are polyesters that are obtained using hydroxy acids as the starting materials, which are derived from renewable resources and biowaste. These biopolymers have attracted a lot of attention since some of them will be in a near future competitive in price to polyolefins, show excellent mechanical and barrier properties, and can be potentially recycled by physical and chemical routes. Most of the current poly(hydroxy acids) are mainly prepared by ring opening polymerization (ROP) of cyclic monomers derived from hydroxy acids. However, their direct polymerization has received much less attention, while one of the advantages of hydroxy acids resides in the presence of an electrophile and a nucleophile in a single molecule that makes them ideal A-B type monomers for selfcondensation. This review focuses on the preparation of poly(hydroxy acids) by the self-condensation polymerization of hydroxy acids. Moreover, their end-of-life options are also evaluated considering not only their biodegradability but also their potential to be chemically recycled.
\end{abstract}

\section{Introduction}

Polymers have become a ubiquitous type of material that is used in a wide range of applications since the first industrial synthesis of plastics in XX century with the pioneering work of W. Carothers ${ }^{1}$. Plastics, that is, polymer and additives, are not only the material of choice for large application sectors such as packaging (nearly 150 million tons/year), building and construction (65 million tons/year), textile clothing (50 million tons/year) or automotive (30 million tons/year), but they are also a key player when designing materials for high added value sectors such as aerospace, membranes or

a. Department of Polymer Science and Technology, Institute for Polymer Materials (POLYMAT), Faculty of Chemistry, University of the Basque Country (UPV/EHU) Paseo Manuel de Lardizabal 3, 20018 Donostia, Spain.

b. Novel Materials and Nanotechnology Group, Institute of Agrochemistry and Food Technology (IATA), Spanish National Research Council (CSIC), Calle Catedrático

Agustín Escardino Benlloch 7, 46980 Paterna, Valencia, Spain.

+ Footnotes relating to the title and/or authors should appear here.

Electronic Supplementary Information (ESI) available: [details of any supplementary information available should be included here]. See DOI: 10.1039/x0xx00000x biomedical devices ${ }^{2,3}$. This versatility arises mainly from the continuous and unique development of polymers during the last 100 years that has fueled the design of plastics ranging from soft to hard, from brittle to elastic or from transparent to colored. Thus, in 2018, the production level of plastics was accounting roughly 400 million tons and it is expected to rise over 1,000 million tons in $2050^{2}$. While tremendous efforts have been devoted in the last century to enhance the properties of plastics and to promote their further use, only recently concerns have raised about the problem derived from the long durability of plastics ${ }^{4,5}$. This issue is particularly critical in sectors where they are intended to be used for short period of times, such as in the packaging industry, which accounts for approximately $40 \%$ of the total plastic production ${ }^{2}$.

Packaging is essential to preserve food quality and safety but also has raised serious criticism from society, which is demanding more sustainable alternatives to our current plastic model. Nevertheless, in spite of the use of plastics for food preservation, it 
is estimated that around $30-40 \%$ of food is currently being wasted in developing and developed countries. This is the paradox of the packaging sector: while packaging can fuel the prevention of food waste and should ensure the feeding of the continuously growing population, it is highly denigrated by our society ${ }^{6,7}$. It is clear that our current model of plastic production is far from being sustainable and different measures must be taken, being one of them the development of packaging articles that allow protecting and preserving food without destroying our planet.

Nowadays the most employed materials in the packaging sector are polyethylene (PE), polypropylene (PP), polystyrene (PS), polyethylene terephthalate (PET), and polyamides (PAs). However, these materials are habitually not bio-based and also not biodegradable. This makes them difficult to recycle once they reach the end of life, being disposed and accumulated in the environment ${ }^{2,4}$. In this regard, governments and industries are aware about the tremendous problems coming from disposed plastics and highly challenging initiatives have been already taken. For instance, the European Union (EU) intends that by 2030 all the plastics used in packaging applications are recyclable in a cost-effective manner and, in this regard, the 25-top packaging industries have agreed to use at least $25 \%$ of recycled material in their packaging articles. Polyesters have attracted a lot of attention among the materials of choice with potential to be recycled since some of them can be competitive in price to polyolefins, present excellent mechanical and medium barrier properties, and it can also be derived from biomass. In addition, some can degrade in the environment under certain conditions and this fact is important if the materials escape from the collecting system. While in the last years continuous efforts have been devoted to design polyesters that have good properties with reduced production costs, nowadays the recyclability of the polyesters should also be carefully evaluated to further determine their potential 8,9 .

In spite of some current laboratory development to produce polyesters by radical mediated polymerizations, three main methods are conventionally used to produce polyesters, namely ring-opening polymerization (ROP) of cyclic esters, step-growth polymerization of diacids and diols (and derivatives), and self-polycondensation of hydroxy acids ${ }^{1,10,11}$. These methods are summarized in Figure 1. Among these methods, the polymerization of cyclic monomers by
ROP has attracted a great attention since it is a simple method to obtain high-molecular weight $\left(\mathrm{M}_{\mathrm{w}}\right)$ polyesters. ROP follows chain growth kinetics since the monomer is added to the active chain end and the polymerization can proceed by acyl-oxygen or alkyl-oxygen scission. A wide range of different cyclic esters have been synthesized by ROP such as polylactide (PLA) and poly( $\varepsilon$ caprolactone) (PCL). The main advantage of this polymerization route is related with its ability to obtain well-defined polymers with narrow polydispersities and high $M_{W}$. Nevertheless, as cyclic monomers are required to perform the polymerization, the polymerization is limited to monomers able to be polymerizable by means of ROP1,10-14. Moreover, in many cases, the preparation of the cyclic monomer is not straightforward and complex multi-step synthesis is required to obtain the desired cyclic structures.

Besides chain-growth polymerization (e.g. ROP), polyesters can also be prepared using the step-growth polymerization approach. Thus, the polycondensation of diacids or diesters with diols represents the most investigated and industrially relevant route for the production of polyesters. The main advantage of this method is based on the fact that there is a wide range of these monomers available that provide access to a plethora of new polyesters, without the need of additional cyclization step, making the process more economically affordable and less time consuming than ROP. However, it also has some disadvantages. For instance, this process requires harsh polymerization conditions, such as high temperatures, vacuum to remove condensate, and exquisite control of the stoichiometry to achieve high $\mathrm{M}_{\mathrm{W}}$. $^{1,10,11,15}$.

As mentioned earlier, polyesters can also be obtained by the self-polycondensation of hydroxy acids. The main advantage of this method in comparison with the conventional step-growth polymerization of diacids and diols lies in the fact that there is not need to control the stoichiometry. Consequently, with an appropriate setup in terms of polymerization conditions, that is, good control of temperature, a high-performance catalyst, and vacuum, high $M_{w s}$ can be obtained. Despite this benefit, the use of the self-condensation to produce polyesters remains underexplored when compared with step-growth polymerization or ROP.

The main focus of this review is to provide key aspects related to the preparation of polyesters from the self-condensation of hydroxy acids to incentivize their further use. This review will have a 
particular focus on the open literature related with the new trends based on the preparation of polyesters using hydroxy acids. Thus, in the first part of the review, the different hydroxy acid families and their natural origin will be discussed. In the second part, the different catalysts that have been used to polymerize these hydroxy acids will be summarized. In addition, special attention will be paid to the end of life of these polyesters prepared from hydroxy acids.

polymerization

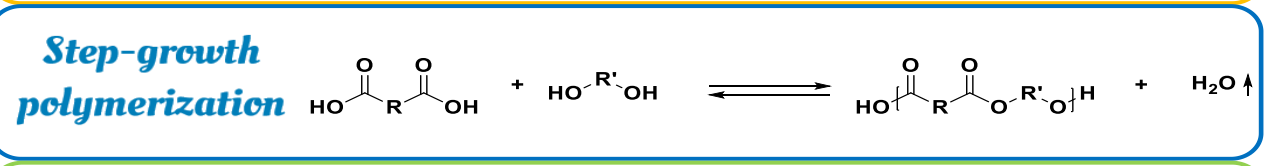

Self-condensation polymerization carboxylic acids so that they are habitually weak acids. However, their chemical structure enables them to form internal hydrogen bonds between the hydrogen of the alcohol group and one of the oxygen of the acid groups. That characteristic makes the acid proton to be less strongly attached and, therefore, the pKa of these compounds is lower than their analogue acids molecules ${ }^{16}$.

Figure 1. Main polymerization methods of poly(hydroxy acids).

\section{Hydroxy acids monomers and classification}

One of the main benefits of hydroxy acids is that they naturally occur in plants, such as sugar cane, tomatoes, oranges, lemons, grapes, and apples as well as in animal tissues. Since ancient times, human civilization uses some hydroxy acids in form of crude extracts of plants for curing many inflammation and diseases mainly due to the presence of salicylic acid as an active ingredient. Therefore, formulations containing hydroxy acids have been widely used in clinical practice for decades to treat a variety of skin infections. These acids have a broad range of application in various fields including cosmetics, pharmaceutical, and food industries. In cosmetics, hydroxy acids are used for the treatment of various skin diseases such as in photoaging, acne, pigmentation disorders, and psoriasis. A wide range of pharmaceutically important chiral synthons are also being synthesized using hydroxy acids as precursor, for instance mandelic acid that is used in the synthesis of antitumor agents, antiobesity agents, semi-synthetic penicillin, and cephalosporin.

Another interesting feature of hydroxy acids is that they have, at least, one nucleophile (alcohol group) and one electrophile (carboxylic acid group) in the monomeric structure allowing its selfcondensation. Thus, these monomers have been investigated as a renewable source for biopolyesters synthesis by polycondensation reactions. The acidity of these molecules is related to their equivalent
Hydroxy acids can be classified taking into account the position of the alcohol group in the carboxylic chain and also the number of the functional groups ${ }^{17}$. As a result, these can be then divided into $\alpha-, \beta-, \omega_{-}$, aromatic or polyhydroxy/polycarboxy acids. Figure 2 shows the chemical structures of the types of different hydroxy acids.

$\alpha$-hydroxy acids have a hydroxyl group in the $\alpha$-carbon of the main chain. The monomers of this group of hydroxy acids are the ones that have been most studied to carry out the polymerization process. The largest used $\alpha$-hydroxy acid is lactic acid, which is industrially obtained from sour milk and it can be used to synthesize polylactic acid (PLA). Nowadays, this biopolyester is industrially obtained by ROP of lactide so that it is most accurately termed polylactide. The lactic acid dimer can be isolated into three forms, namely the optically active L-lactide, the optically active D-lactide, and the optically inactive isomer mixture $D, L$-lactide. PLA grades with the -isomer, that is PLLA, are semicrystalline, whereas the ones with $>15 \%$ D-isomer and the racemic mixture are amorphous. ${ }^{18}$ It currently shows an annual consumption over 140,000 tons, being considered the front runner in the bioplastics market ${ }^{19}$. 


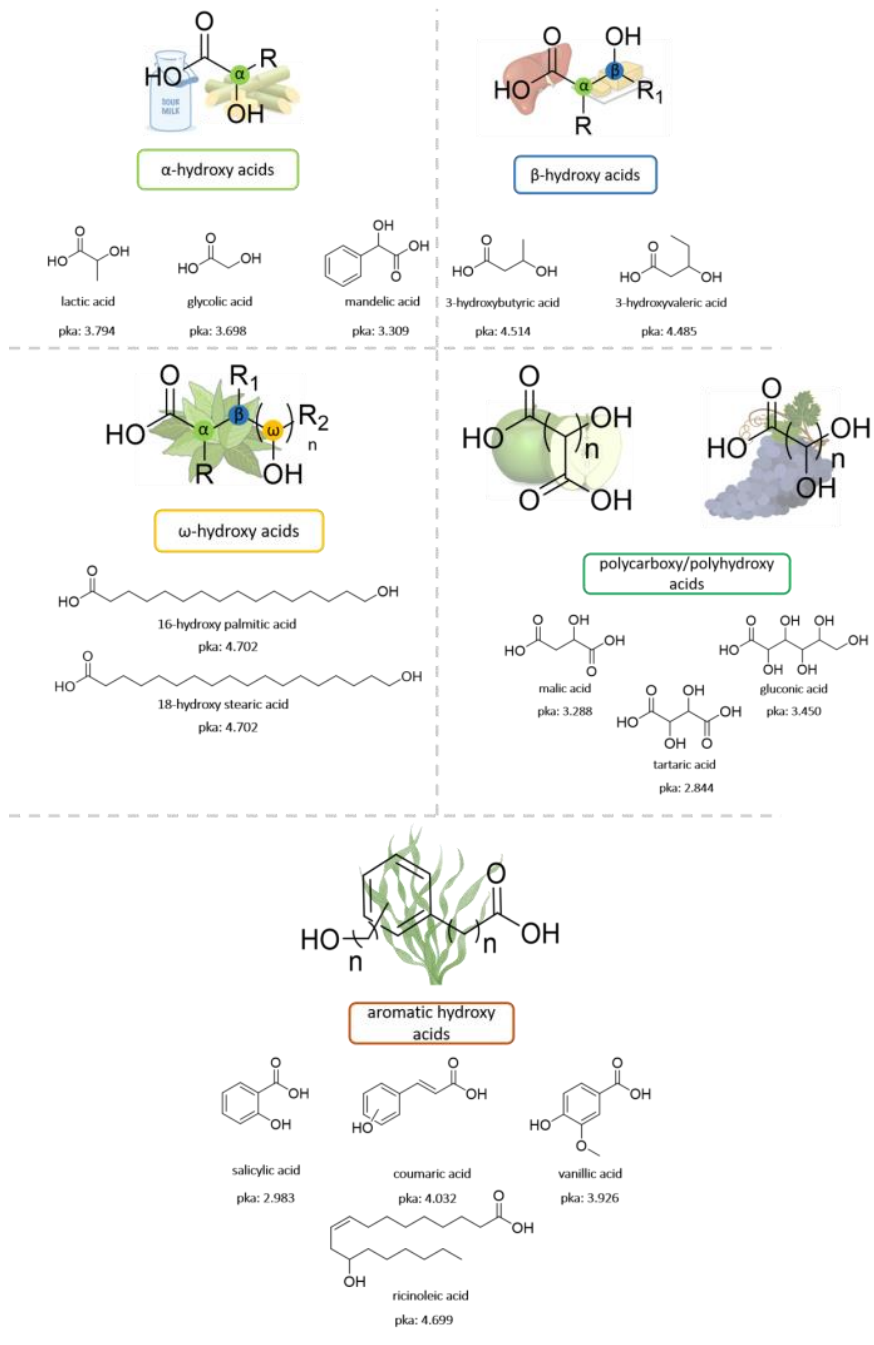

Figure 2. Classification of hydroxy acids.

Another $\alpha$-hydroxy acid that has been investigated in the field of cosmetics is glycolic acid due to both its bioavailabity, it is present in sugar cane, and biocompatibility. This hydroxy acid is the smallest as it is constituted only by 2 carbons $^{16,20}$. In addition, it is used in the textile industry as a dyeing and tanning agent and also in food processing as a flavoring and preservative. It is also included in ink and paints to improve flow properties and impart gloss. Another available $\alpha$-hydroxy acid is mandelic acid, which has a long history of use in the medical community as an antibacterial agent, particularly in the treatment of urinary tract infections. It has also been used as an oral antibiotic. It can be obtained from almonds and it has been copolymerized with lactic acid, though it has never been homopolymerized ${ }^{21}$.

$\beta$-hydroxy acids are the second largest used hydroxy acids. In this family, the alcohol group appears separated from the carboxyl group by two carbon atoms. They are used as starting materials to synthesize vitamins and antibiotics as well as some other optically active bioactive compounds. The most known $\beta$-hydroxy acids are 3 hydroxybutyric acid (3HB) and 3-hydroxyvaleric acid (3HV), which are produced in the liver via the metabolism of fatty acids. These molecules have lower pKa values than the carboxylic acids and also than $\alpha$-hydroxy acids, though these do not have a correlation with their reactivity. This is due to the longer distance between the hydroxyl and carboxylic group and consequently they are not that likely to form the hydrogen bonds ${ }^{16,20}$. These two hydroxy acids could potentially be used in a near future to synthetize polyhydroxyalkanoates (PHAs), which nowadays are mainly produced by bacteria in bioreactors and show excellent barrier properties ${ }^{22}$. The most studied However, their high crystallinity and their brittle behavior have limited their applicability in packaging sectors unless they are mixed with other biopolymers or modified to reduce their cristallinity ${ }^{23}$.

Additionally, the rest of the aliphatic hydroxy acids are included in the group of $\omega$-hydroxy acids. They have in common three or more carbon atoms between the alcohol and the acid group. This group includes 16-hydroxy palmitic acid and 18-hydroxy stearic acid. These monomers mainly appear in the cutin of the plant cuticle. In addition, some other $\omega$-hydroxy acids can be found in animals, which control some physio-pathological processes ${ }^{17}$. These long-chain hydroxy acids can be the precursors of highly hydrophobic materials that mimic polyethylene but with recyclability built into their performance.

To finish with the hydroxy acids classification, one can also find the aromatic ones such as the well-known salicylic acid, coumaric acid, vanillic acid and ricinoleic acid or the multi-functional hydroxy acids such as malic acid, tartaric acid or gluconic acid. The aromatic hydroxy acids (ArHAs) are compounds that have an aromatic group and the carboxyl and hydroxyl groups are attached to it. The coumaric acid, the salicylic acid, the vanillic acid and the ricinoleic acid are known to be present in vinegar, white willow, argan oil and castor oil respectively. All of them have been used as valuable compounds in the biomedical field, considering the anti-bacterial property of the coumaric acid, the anti-inflammatory response of ricinoleic acid and salicylic acid ${ }^{16}$. Furthermore, malic acid naturally occurs in many fruits, such as cherries, peaches, and apples. This 
compound has two acid groups and one alcohol group that is in $\alpha$ position respect to one of the acids and in $\beta$-position respect to the other one. Another interesting hydroxy acid is gluconic acid, which could be found in fruits and wine, and it has five alcohol groups and one carboxylic group. Naturally, there are also some compounds that fall in the group of polyhydroxy/polycarboxy acids, which is the case of tartaric acid that is formed by two alcoholic and two acidic groups $^{16,20}$.

\section{Polymerization of hydroxy acids}

Polymerization of the hydroxy acid monomers is very versatile and it highly depends on the monomer and the catalyst types that are used during this process. Despite polyesters derived from hydroxy acids can be obtained without the need of a catalyst, the use of a catalyst is highly desired to increase the reaction rate and then attain high $\mathrm{M}_{\mathrm{W}} \mathrm{s}$ in shorter times. As previously mentioned, besides selecting an optimum catalyst, the polymerization conditions such as temperature or vacuum are also a crucial factor to achieve poly(hydroxy acids) with desired properties. Indeed, high temperatures are usually required to reduce the viscosity of the media and enhance the elimination of water during polymerization ${ }^{24}$.

Hydroxy acids polymerization is mainly based on Fischer esterification reactions, which allows the reaction between alcohols and acids in the presence of acid catalyst, though it can also be catalyzed by a number of different catalysts including enzymes and metals ${ }^{25}$. However, among the studied catalysts, the most optimal results have been so far achieved by acids ${ }^{24}$. Polymerization of hydroxy acids is based on the mechanism described in Figure 3. Briefly, the reaction is initiated due to the electrophilic activation of the carbonyl group by the acid. Subsequently, the activated carbonyl is attacked by the alcohol group, forming an intermediate that releases water after a proton transfer occurs. As it is a reversible reaction, the removal of water is a crucial step to push the conversion and to guide the equilibrium to the ester. Therefore, in all these polymerization reactions, high vacuum together with elevated temperatures is habitually applied to the reaction media to promote the water removal. The temperature should be well controlled at the beginning of the polymerization, due to the lower boiling points of the monomers. Once the first oligomers have been synthesized, the reaction temperature needs to be increased to enhance the polymerization. One of the key features of polymers formed by the self-condensation of hydroxy acids is the potential of these polymers to be fully recycled in a Circular Economy approach as this polymerization is reversible. By properly selecting the conditions, the polymer-monomer equilibrium can be guided to the monomer species, enabling the recovery of the initial monomers.

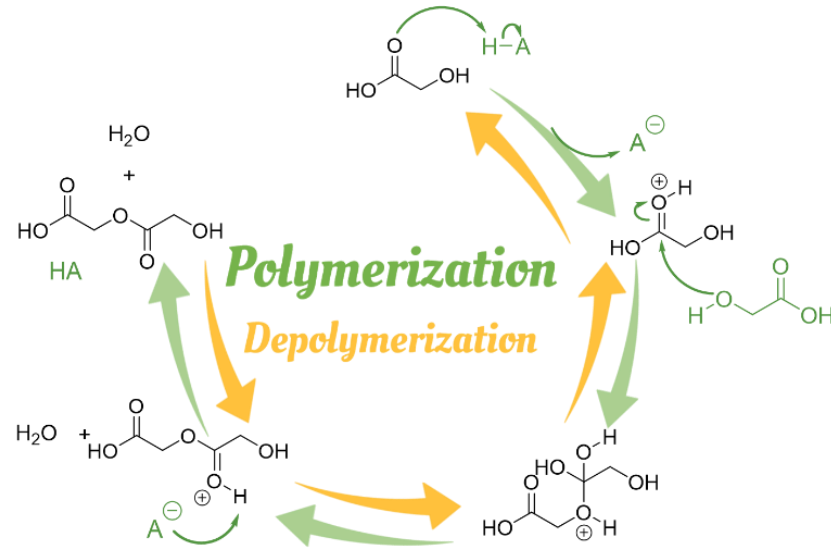

Figure 3. Fisher esterification mechanism for the polymerization and depolymerization of poly(hydroxy acids).

The main catalysts used for the polymerization of hydroxy acids can be metals, organic materials, and enzymes. These are illustrated in Figure 4. The following lines in this section describe some examples about the most successful catalysts employed, so far, for the polymerization of biopolyesters derived from hydroxy acids. These are classified according the type of hydroxy acid. 


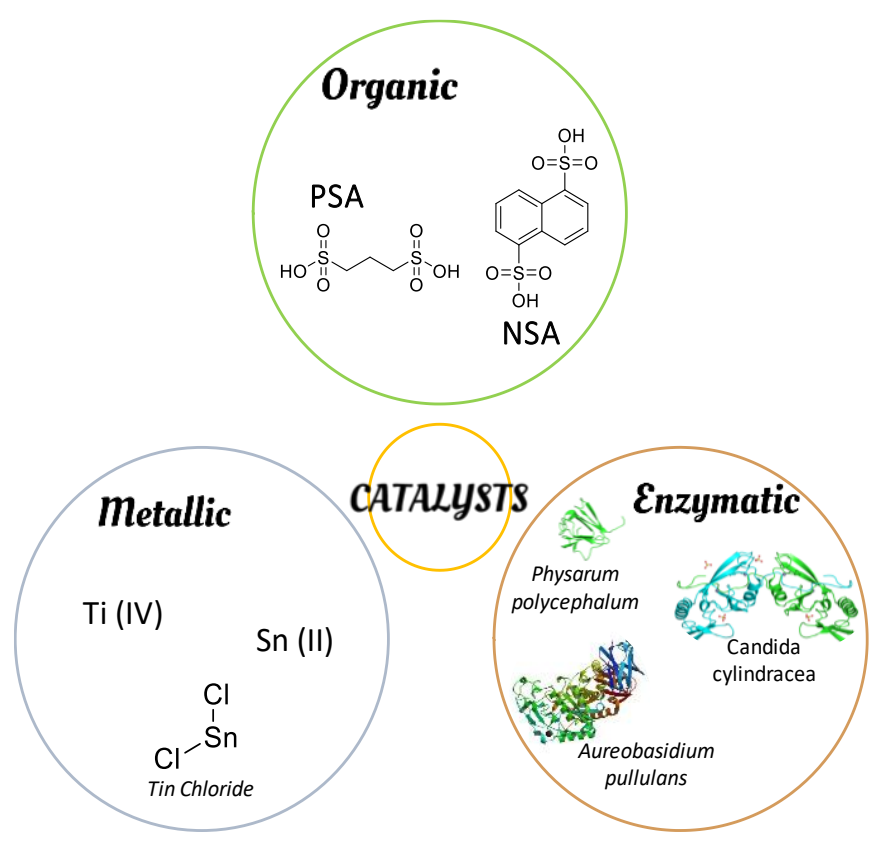

Figure 4. The three main types of catalysts used to polymerize hydroxy acids: transition metals such as titanium (Ti) and tin (Sn), organic materials such as 1,3-propanedisulfonic acid (PSA) and 1,5naphthalene disulfonic acid (NSA), and enzymes.

\section{Polymerization of $\alpha$-hydroxy acids}

Lactic acid and glycolic acid are the most studied hydroxy acids for the synthesis of biopolyesters, being of high interest in the packaging and biomedical industries due to their natural origin and biodegradable property ${ }^{26}$. However, it is highly challenging to introduce functional groups into conventional poly( $\alpha$-hydroxy acids) (PAHAS) derived from lactides and glycolides to yield functional biopolyesters with more controlled $\mathrm{M}_{\mathrm{w}}$ and a variety of functionalities for widespread utilities and biological applications. In this regard, recent efforts have been devoted to the development of PAHAS by the ROP of O-carboxyanhydrides (OCAs), a class of fivemembered cyclic anhydrides derived from amino acids. REF1

Table 1 shows some examples of the polymerization methods carried out to produce PLA and the $\mathrm{M}_{w}$ that have been obtained. Due to the difficulty in removing by-products completely from the highly viscous reaction mixture, PLA produced through direct polycondensation is usually of low $\mathrm{M}_{\mathrm{W}}\left(<5 \times 10^{4} \mathrm{~g} / \mathrm{mol}\right)^{27}$ and it is currently restricted for biomedical applications (e.g. bioresorbable items). Although ROP is able to yield PLA with $M_{w}$ values of up to over $4.5 \times 10^{5} \mathrm{~g} / \mathrm{mol}^{28}$, commercial grades used in the packaging field due to not typically exceed $2 \times 10^{5} \mathrm{~g} / \mathrm{mol}$. Broadly speaking, PLA grades for packaging applications can be divided into injectionmolding grades (typically $\mathrm{M}_{\mathrm{w}}$ of $1.1-1.3 \times 10^{5} \mathrm{~g} / \mathrm{mol}$ and $\mathrm{M}_{\mathrm{n}}$ of 8-9 $\times 10^{4} \mathrm{~g} / \mathrm{mol}$ ) and extrusion grades ( $\mathrm{M}_{\mathrm{w}}$ of $1.5-1.8 \times 10^{5} \mathrm{~g} / \mathrm{mol}$ and $M_{n}$ of $\left.0.9-1.1 \times 10^{5} \mathrm{~g} / \mathrm{mol}\right)$, having polydispersity index $\left(P I, M_{w} / M_{n}\right)$ values of approximately 1.4 and 1.5, respectively ${ }^{29}$. In turn, the extrusion PLA grades can be sub-divided into fiber spinning, film/sheet, foaming, 3D printing, etc ${ }^{27}$. Commercial PLA grades for injection molding have thus much lower viscosities than extrusion ones, which is achieved not only by using lower $M_{w}$ s but also plasticizers or impact modifiers ${ }^{30}$.

Among catalyzers, metals constitute the most used catalysts at the industrial scale due to their high efficiency. Metallic catalysts are thermally stable and have high reactivity, which makes them useful in polycondensation reactions ${ }^{31}$. Their high catalytic activity provides polymers with high $\mathrm{M}_{\mathrm{w}}$ in short reaction times during polycondensation, however they are not comparable with the ones obtained by ROP. For the polymerization of hydroxy acids, the most used catalysts contain transition metals, such as titanium (Ti) and tin (Sn). The selected metals have to be able to change the oxidation number during the reaction. For instance, tin chloride $\left(\mathrm{SnCl}_{2}\right)$ is the one most used to synthesize PLA by polycondensation of lactic acid due to its high performance ${ }^{32}$. This reaction has to be carried out at high temperatures, around $180^{\circ} \mathrm{C}$, in order to obtain $\mathrm{M}_{\mathrm{W}}$ values of around $3 \times 10^{5} \mathrm{~g} / \mathrm{mol}$ after $20 \mathrm{~h}$. However, the use of these catalysts gives racemization and discoloration to the final material. In order to optimize the polycondensation reaction of AHAs, p-toluenesulfonic acid or phosphorous acid have been added together with the $\mathrm{SnCl}_{2}$ catalyst. The use of a binary catalyst provides PLA materials with a $\mathrm{M}_{\mathrm{W}}$ of around $6 \times 10^{4} \mathrm{~g} / \mathrm{mol}^{33}$.

Since the $M_{w s}$ attained by polycondensation are still far from the ones that could be obtained by ROP, Moon et al. ${ }^{32}$ carried out a solid-state polycondensation (SSP) after melt polycondensation. SSP is a type of polymerization performed under vacuum at temperatures below the melting temperature $\left(T_{m}\right)$ of the polymer (for instance in the case of PLA it is performed at $160^{\circ} \mathrm{C}$ ) to achieve a polymer of high $\mathrm{M}_{\mathrm{W}}$ with uniform and consistent intrinsic viscosity. By this method, PLA with a $M_{W}$ in the order of $5 \times 10^{5} \mathrm{~g} / \mathrm{mol}$ was successfully obtained ${ }^{34}$. SSP is also an appropriate technique to obtain high-Mw poly(glycolic acid) ${ }^{35}$. Another way to increase the $M_{w}$ 
values up to $3 \times 10^{5} \mathrm{~g} / \mathrm{mol}$ is the use of a high boiling point solvent, such as xylene, during polymerization. This solvent will decrease the viscosity of the reaction media and, therefore, it would allow an easier removal of water during polymerization guiding the conversion to the poly(hydroxy acid). Another advantage of using this procedure is that the temperature needed to carry out the reaction can be reduced down to $130{ }^{\circ} \mathrm{C}$, which can decrease considerably the number of side reactions ${ }^{36}$.

In spite of the benefits of using metal catalysis such as Sn (II) to obtain PLA, there are also some important drawbacks such as the cytotoxicity and environmental impact of this catalyst after biodegradation ${ }^{37}$. This fact has fueled to find more environmentally benign alternatives for synthesizing poly(hydroxy acids) from $\alpha$ hydroxy acids. In this regard, the use of enzymes for the polymerization processes is gaining interest in the last years since they show promising advantages compared to metals such as mild reaction conditions, no toxicity, and high selectivity. In addition, they have high enantio- and regioselectivity, which enables to synthesize precise polymers ${ }^{38}$. This selectivity comes from their unique three dimensional structure that forces the monomer to polymerize in a specific way ${ }^{39}$. For instance, Chuensangjun et al. ${ }^{40}$ reported the use of lipase enzyme for the synthesis of PLA. This kind of catalyst did not yield undesirable toxic residues and, therefore, it can be a promising catalyst for biomedical applications. In this case, the polycondensation requires to be performed in solution to avoid high reaction temperatures and, consequently, the denaturalization of the protein. It should be noted that the results indicated that low $\mathrm{Mw}_{\mathrm{w}}$ PLA were produced, up to $8 \times 10^{3} \mathrm{~g} / \mathrm{mol}$, from commercial lactic acid by using the commercial lipases.

Organic catalysis has gained popularity in recent years due to their relatively low cost and versatility. Comparing with metals, organocatalysts generally exhibit better tolerance to moisture and air ${ }^{41}$, however higher catalysts loadings and longer reaction times are required to compete with the superior activity of their metallic counterparts. The first utilization of organocatalysts for polymerization was encouraged from the necessity of a non-toxic catalyst to synthesize polymers for biomedical applications and/or microelectronics ${ }^{15}$. While at their infancy they were mainly employed in chain-growth polymerizations, an emerging focus on the use of organocatalysts in step-growth polymerization has appeared over the last years, including the synthesis of polyurethanes ${ }^{42}$, polyesters ${ }^{43}$, polyethers ${ }^{44}$ or polycarbonates ${ }^{45}$. Another key advantage of organocatalysts is that they can be removed from the resultant polymer due to they are not strongly bounded to the polymer ${ }^{46,47}$. In addition, they can be reused to catalyze another reaction without losing significant effectivity $24,37,48$.

In the middle of the $20^{\text {th }}$ century, Filachone et al. ${ }^{49}$ determined that acids activate the polycondensation of hydroxy acids. They used boric and sulfuric acids to homopolymerize lactic acid by melt polycondensation. These catalysts succesfully accelerated the polycondensation reaction. However, at high temperatures, they were not thermally stable and they promoted side reactions, leading to $M_{W}$ values around $3 \times 10^{3} \mathrm{~g} / \mathrm{mol}^{50}$. Thereafter, Lunt et al. ${ }^{39,24}$ incorporated an azeotropic solvent to decrease the temperature of the reaction media. By this method, the viscosity of the reaction decreased and the removal of water was substantially improved, making feasible the synthesis of PLA of $2.4 \times 10^{4} \mathrm{~g} / \mathrm{mol}$. The melt polycondensation reaction process can be combined subsequently by solid polycondensation in order to achieve higher $\mathrm{M}_{\mathrm{w}}$. Thus, BoGeng et al. ${ }^{37}$ used sulfonic acid catalysts to carry out the melt/solid polycondensation. It was shown that the use of organocatalysts in solid polycondensation has considerable advantages comparing with the metallic ones since they do not yield yellowish and the thermal stabilities of the biopolyesters are comparable with the ones obtained by ROP. In particular, the use of 1,5-naphthalene disulfonic acid (NSA) and 1,3-propanedisulfonic acid (PSA) catalysts showed good performance and resulted in PLA materials with $\mathrm{M}_{\mathrm{W}}$ s around $8.2 \times 10^{4} \mathrm{~g} / \mathrm{mol}$. However, the need of elevated temperatures has hindered the use of organic catalysts in the polymerization of biopolyesters derived from hydroxy acids due to their inferior thermal stability ${ }^{47}$.

In addition of the homopolymerization of $\alpha$-hydroxy acids, some copolymers such as poly(lactic-co-mandelic acid) (PLMA), poly(lacticco-phenyllactic acid) (PLPhA), and poly(lactic-co-glycolic acid) (PLGA) have also been successfully synthesized. It was observed that the polymerization of these copolyesters needs longer reaction times and higher temperatures, yielding low $\mathrm{M}_{\mathrm{w}}$. In order to enhance the polycondensation reaction diphenyl ether was used as solvent during polymerization $^{51,52}$. 


\section{REVIEW}

Table 1. Comparison of the molecular weights ( $\mathrm{M}_{\mathrm{WS}}$ ) of poly(lactic acid) (PLA) obtained by different methods.

\begin{tabular}{|c|c|c|c|c|}
\hline Catalyst & Temperature & Solvent & Process & $\mathrm{M}_{\mathrm{w}}(\mathrm{g} / \mathrm{mol})$ \\
\hline Tin chloride $\left(\mathrm{SnCl}_{2}\right)$ & $180^{\circ} \mathrm{C}$ & - & Melt polycondensation & $3 \times 10^{4}$ \\
\hline $\begin{array}{l}\text { Binary catalyst }\left(\mathrm{SnCl}_{2}+\right. \\
\text { acid })\end{array}$ & $180{ }^{\circ} \mathrm{C}$ & - & Melt polycondensation & $6 \times 10^{4}$ \\
\hline Tin chloride $\left(\mathrm{SnCl}_{2}\right)$ & $130{ }^{\circ} \mathrm{C}$ & $\begin{array}{c}\text { High boiling point } \\
\text { solvent }\end{array}$ & $\begin{array}{c}\text { Solution } \\
\text { polycondensation }\end{array}$ & $3 \times 10^{5}$ \\
\hline Tin chloride $\left(\mathrm{SnCl}_{2}\right)$ & $160{ }^{\circ} \mathrm{C}$ & - & $\begin{array}{c}\text { Solid-state } \\
\text { polycondensation (SSP) }\end{array}$ & $5 \times 10^{5}$ \\
\hline Lipase enzyme & $50^{\circ} \mathrm{C}$ & Toluene & Enzymatic reaction & $8 \times 10^{3}$ \\
\hline $\begin{array}{l}\text { Acids (boric acid, sulfuric } \\
\text { acid) }\end{array}$ & $180^{\circ} \mathrm{C}$ & - & Melt polycondensation & $3 \times 10^{3}$ \\
\hline $\begin{array}{l}\text { Acids (boric acid, sulfuric } \\
\text { acid) }\end{array}$ & $130{ }^{\circ} \mathrm{C}$ & Azeotropic solvent & $\begin{array}{c}\text { Solution } \\
\text { polycondensation }\end{array}$ & $2.4 \times 10^{4}$ \\
\hline Sulfonic acids & $160{ }^{\circ} \mathrm{C}$ & - & $\begin{array}{c}\text { Solid-state } \\
\text { polycondensation (SSP) }\end{array}$ & $8.2 \times 10^{4}$ \\
\hline
\end{tabular}

\section{Polymerization of $\beta$-hydroxy acids}

After PAHAS, poly( $\beta$-hydroxy acids) (PBHAS) represent the second largest biopolyesters that can be obtained from hydroxy acids. In this regard, $\beta$-hydroxy acids are interesting synthetic targets as they can be the precursors to produce poly(3-hydroxybutyrate) ( $\mathrm{P} 3 \mathrm{HB}$ or $\mathrm{PHB})$, which has shown extraordinary oxygen barrier properties together with fast biodegradability. One of the biggest interest of PHB is related to the fact that it has similar mechanical properties than PET but it is less hydrophobic and, therefore, it has high potential as sustainable packaging material ${ }^{53}$. PHB is produced industrially through fermentation of glucose by the bacterium
Alcaligenes eutrophus, though it can also be produced by hundred species of Gram-positive ( $\mathrm{G}+$ ) and Gram-negative (G-) bacteria under famine regimen conditions ${ }^{54}$. This biological process leads to an optically active biopolymer with a perfect configuration. Due to the high precision of the biological route, the crystallinity of the biopolyester can reach degrees above $95 \%$. However, its high crystallinity results in a brittle and hard article with limited applications ${ }^{23}$. In this sense, the incorporation of a comonomer, for instance $3 \mathrm{HV}$, helps to improve its properties. The resultant poly(3hydroxybutyrate-co-3-hydroxyvalerate) (PHBV) copolyester shows better physical properties in terms of lower $T_{m}$ and higher flexibility and toughness ${ }^{55}$. Alternatively, copolymerization of $3 \mathrm{HB}$ units with 4- 
hydroxybutyrate (4HB) units yields poly(3-hydroxybutyrate-co-4hydroxybutyrate) (P(3HB-co-4HB $))^{56}$. Different ratios of $3 \mathrm{HB}$ versus $4 \mathrm{HB}$ can be achieved depending on the type of microorganism and supplied carbon substrates ${ }^{57}$. The introduction of different comonomer units induces defects in the crystal lattice, reducing both the degree of crystallinity and crystallization rate ${ }^{58}$ and, thus, the processing window is improved. As a result, PHAs are nowadays regarded as the most promising candidates to replace polyolefins in packaging applications ${ }^{59}$.

In 1995, Gerngross et al. ${ }^{60}$ showed the first enzymatic cell-free synthesis of PHB based on the use of purified PHA synthase (PhaC), which is the key enzyme involved in PHA biosynthesis and functions by polymerizing monomeric hydroxyalkanoate substrates. PHA synthases have been traditionally categorized into four major classes based on their primary sequences, substrate specificity, and subunit composition ${ }^{61}$. Class I comprises enzymes consisting of only one type of PhaC, which forms a homodimer. Class II contains two types of synthases, that is, PhaC1 and PhaC2. Class III and IV synthases form heterodimers such as PhaC-PhaE and PhaC-PhaR, respectively. Whereas class I, III and IV synthases tend to favor short-chain-length $(s c l)$ monomers comprising C3-C5 carbon chain lengths, for instance $3 \mathrm{HB}$, Class II synthases favor medium-chain-length $(\mathrm{mcl})$ monomers comprising $\mathrm{C} 6-\mathrm{C} 14$ carbon chain lengths, which is the case of the C6 monomer 3-hydroxyhexanoate $(3 \mathrm{HHx})^{62}$. Subsequently, other groups have evolved the chemosynthesis in terms of monomer supply and polymer yield. The so-called cell-free synthesis is useful not only for polymer production, but also for the functional analysis of PhaC. In this context, the ROP of $\beta$-butyrolactone $(\beta-B L)$ and $\gamma$ butyrolactone ( $\gamma-\mathrm{BL}$ ) has been developed for the chemical synthesis of $\mathrm{P}_{3} \mathrm{HB}^{63}$ and $\mathrm{P} 4 \mathrm{HB}^{64}$. However, despite extensive research efforts since the 1960s, the chemical synthesis of P3HB with high isotacticity and $M_{w}$ via ROP of $\beta-B L$ has proven elusive. Inspired by the ROP of the racemic lactide, Chen et al. ${ }^{65,66}$ recently realized the synthesis of perfectly isotactic P3HB by the stereoselective ROP of the racemic eight-membered cyclic diolide ( $r a c-8 D L$ Me, the superscripted "Me" denotes methyl substituents on the $8 \mathrm{DL}$ ring) derived from biosourced dimethyl succinate using racemic yttrium catalysts (1-4) supported by C2-symmetric N,N'-bis(salicylidene) cyclohexanediimine (salcy) ligands. In particular, the racemic catalyst 4 with bulky trityl groups installed at the ortho-phenoxy positions of the salcy ligand produced perfectly isotactic $\mathrm{P} 3 \mathrm{HB}$ with a high $\mathrm{T}_{\mathrm{m}}$ of up to $171^{\circ} \mathrm{C}$, a molecular weight in number $\left(\mathrm{M}_{\mathrm{n}}\right)$ of up to $1.54 \times 10^{5}$ $\mathrm{g} / \mathrm{mol}$, and PI value of $\sim 1$ (typical values for bacterial P3HB are $M_{w}$ of $3-4 \times 10^{5} \mathrm{~g} / \mathrm{mol}, \mathrm{Mn}$ of $1-2 \times 10^{5} \mathrm{~g} / \mathrm{mol}$, and PI of $\left.2-3\right)^{\text {REF2 }}$ under ambient conditions ${ }^{65}$. They also developed the diastereoselective polymerization methodology to enable the direct polymerization of diastereomeric mixtures of $\mathrm{rac} / \mathrm{meso}^{-8 \mathrm{DL}} \mathrm{Le}^{\mathrm{Me}}$ at varied $\mathrm{rac} / \mathrm{meso}$ ratios or meso-8DLMe/rac-8DLEt ("Et" for ethyl-substituted $8 \mathrm{DL}$ ) into stereosequenced semi-crystalline it-P3HB-sb-st-P3HB or st-P3HB-sbit-P3HBV with isotactic and syndiotactic stereoblock or tapered stereoblock microstructures. ${ }^{66}$ More importantly, according to these studies, the tunability of these catalyst structures could potentially allow a rapid entry to P3HB-based materials with various tacticities and, thus, adjustable thermal and mechanical properties, predicted $\mathrm{M}_{\mathrm{W}}$, and low PI values.

\section{Polymerization of $\omega$-hydroxy acids, aromatic hydroxy acids, and polycarboxy-polyhydroxy acids}

Some biopolyesters have also being synthesized by the use of $\omega$ - and aromatic hydroxy acids. For instance, D. O'Hagan et al. ${ }^{67}$ polymerized 10-hydroxydecanoic acid using Candida cylindracea lipase in hexane for $48 \mathrm{~h}$ at $37^{\circ} \mathrm{C}$, giving a polymer of 12 repeating
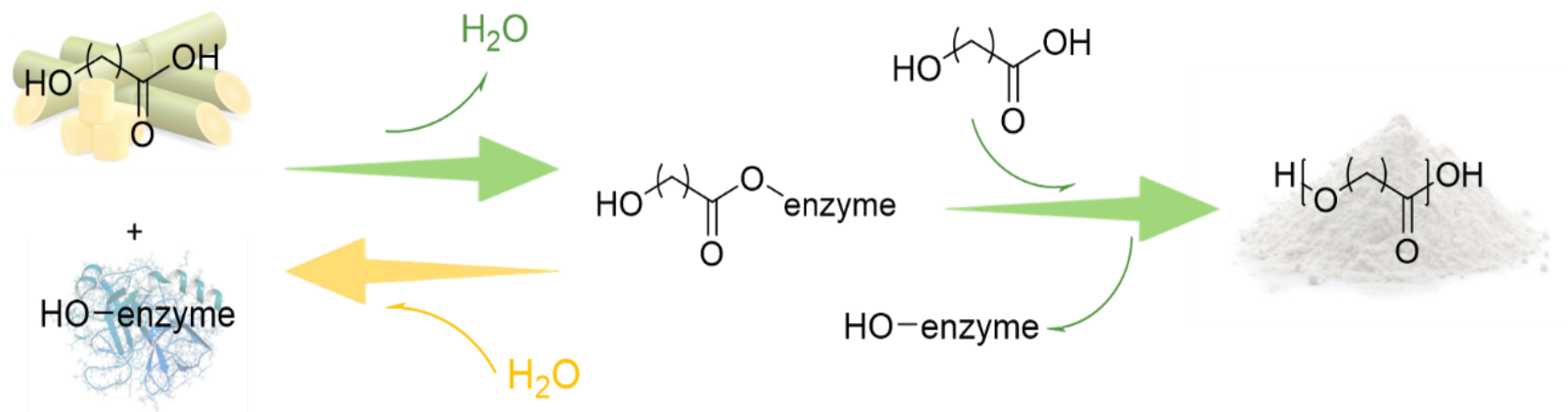

Figure 5. Mechanism of enzymatic polymerization reaction to produce poly(hydroxy acids). 
units. In order to increase the $\mathrm{M}_{\mathrm{w}}$ of the resultant poly(hydroxy) acid, temperature during polymerization was raised to $55^{\circ} \mathrm{C}$ and the final material increased the repeating units up to a value of 52. Similarly, Shuai et al. ${ }^{68}$ reported the polymerization of 3-hydroxybutyric acid and 12-hydroxydodecanoic acid and proposed a possible mechanism. In the scheme described in Figure 5, lipase attacks the carboxylic group of the hydroxy acids and the newly formed bond releases a water molecule. This reaction step is slow because is in the equilibrium. Thereafter, the lipase that is attached to the monomer reacts with the hydroxyl group of another monomer, the lipase is released, and the formation of the polymer starts. However, it has to be taken into account that the Mws obtained by this pathway are only of couple of thousands $\mathrm{g} / \mathrm{mol}$.

Also in relation to $\omega$-hydroxy acids, Croteau and Kolattukudy ${ }^{69}$ copolymerized 16-hydroxy stearic acid and 18-hydroxy stearic acid by a enzymatic synthesis. Despite the homopolymerization of these two abundant $\omega$-hydroxy acids has not been reported, their copolymerization gave rise to copolymers with low $\mathrm{M}_{\mathrm{w}}$. Apart from the aliphatic hydroxy acids, there are also some naturally occurring aromatic ones. However, the polymerization of ArHAs have been hardly studied. For instance, the group of Akashi ${ }^{70}$ in Japan and Serra ${ }^{71}$ in Portugal investigated the homo- and copolymerization of coumaric acid (4HCA) and its derivatives, such as 3-hydroxycinnamic acid (3HCA), 3-methoxy-4-hydroxycinnamic acid (MHCA), and 3,4dihydroxycinnamic acid (DHCA). It was found that producing the homopolymers in bulk conditions was highly detrimental and the double bond of 4HCA almost completely disappeared. Nevertheless, the polymerization outcome was greatly improved by using acetic anhydride as solvent. Thus, it was reported that the homopolymerization of 4HCA could result in a polymer with liquidcrystal properties. It was also studied the copolymerization of 4HCA with lactic acid in order to give functionality to PLA ${ }^{72}$. The resultant materials are expected to have promising properties for their implementation in biomedical and environmental applications ${ }^{73,70}$.

Some poly(esters-amide)s have also been synthesized by the use of vanillic acid and 4-aminobenzoic acid by Kricheldorf et. al. ${ }^{74}$ Ricinoleic acid has also been used to synthesize polyanhydrides for drug release in biomedical applications due to its biodegradability. ${ }^{75}$ One can also consider the group containing more than one hydroxyl or carboxyl group in the monomeric structure, which is named multi- functional hydroxy acids. To the best of our knowledge, these molecules have only been copolymerized with amines or with other ester groups in order to produce copolymers. In spite of the difficulties in the cell-free polymerization, some microorganisms such as Physarum polycephalum and Aureobasidium pullulans, can produce polymalic acid (PMA). The latter biopolymer is biodegradable, has good biocompatible properties, and it is also soluble in water so that it could be used in pharmaceutical, food, and biomedical applications ${ }^{76}$.

\section{End-of-life options}

The same durability properties that have made traditional petroleum derived plastics ideal for many applications, such as those found in food packaging applications, are also leading to terrible waste-disposal problems since polymers are resistant to microbial degradation and plastics highly accumulate in the environment. Fortunately, PLA and PHA, which are currently the most common types of poly(hydroxy acids) found in the plastic industry, fall both categorized as biodegradable and recyclable polymers. "Biodegradation", also called biological degradation, is referred to the conversion of the long-chain molecules (macromolecules) that constitute the polymers into smaller ones by the action of biologically active enzymes produced by specific microorganisms and/or chemical deterioration associated with living microorganisms that utilize them to fulfill their energy requirements ${ }^{77}$. The biodegradability of PHA is attributed to the presence of ester bonds within the PHA molecules that can be hydrolyzed by a large variety of microorganisms. It indeed involves, in most cases, the catalytic activity of microbial enzymes released by microorganisms, which include lipase, proteinase K., pronase, hydrogenase, etc. ${ }^{78,79}$. The biodegradation of polymers is, however, not always complete as a small percentage of it becomes part of microbial biomass, humus, and other natural products ${ }^{80}$.

In this context, different organisms have been reported to be capable of biodegrading PLAs and PHAs into their simple form, whereas some others are capable of utilizing simple monomers subsequently releasing waste products or have the ability to deteriorate the simple excreta ${ }^{78}$. Up to this time, several bacterial and fungal strains have been identified for poly(hydroxy acids). For instance, majority of microbial strains that degrade PHAs belong to bacteria, Streptomyces, and fungi ${ }^{81}$. The ability to degrade PHAs 
depends on the secretion of specific extracellular PHA depolymerases that hydrolyze the biopolymer to water-soluble products. Extracellular PHA depolymerases are also divided into two groups, scl-PHA depolymerases and mcl-PHA depolymerases, which differ with respect to substrate specificity for scl-PHAs or mcl-PHAs. A few bacteria have been reported to degrade both scl-PHAs and mcl-PHAs by producing two types of depolymerases such as Streptomyces exfoliatus $\mathrm{K} 10^{\mathrm{REF3}}$ and Streptomyces $s p . \mathrm{KJ}^{\mathrm{N}} 72^{\mathrm{REF} 4}$. However, the great majority of PHA-degrading microorganisms produce only one type of PHA depolymerase that acts upon either scl-PHAs or mcl-PHAs. Furthermore, microbial enzymes have potential to depolymerize PLA ${ }^{78}$. As an example, PLA was found to be degraded by different strains of Amylocolatopsis and Saccharothrix ${ }^{77}$. Proteinase K. enzyme secreted by Tritirachium album as well as Pseudomonas $s p$. and Rhodococcus $s p$. showed a high ability to decompose PLA ${ }^{82}$. It should be noted that the action of these microorganism is highly influenced by the environmental conditions such as the sea, soil and sludge. The rate of hydrolytic reaction can also be affected by $\mathrm{pH}$ changes that result from the degradation products of polymers, which can alter the microbial growth rate and, thus, the rate of biodegradation. Temperature also plays a major role in biodegradation since excessively low temperatures reduce the growth and activity of microorganisms, while the degradation capacity of enzymes decreases with the temperature increase. The polymer characteristics, such as $M_{w}$ and $T_{m}$, as well as type of additives added to the biopolymers to constitute the bioplastic articles also affect the biodegradation profile ${ }^{78,81}$. For instance, PLA with high values of $M_{W}$ have showed low rates of degradation ${ }^{81}$, while those with low $M_{W}$ values were easily degradable by enzymes ${ }^{83}$. Moreover, some enzymes are known to efficiently degrade biopolyesters that have low $T_{m}$ whereas those polyesters which have high $T_{m}$ are less prone to degradation ${ }^{81}$. In some media, the presence of biosurfactants can additionally promote the biodegradation process of polyesters, even in harsh conditions $^{83,84}$.

From the above, one can consider biodegradability as an addon property for poly(hydroxy acids) that offers additional means of recovery at the end of a product's life. Indeed, while PLA has been regularly considered as biodegradable plastic, recent environmental impact results from landfilling of PLA have showed that only 1 \% degrades over a life span of 100 years ${ }^{85}$. Besides biodegradation, polyesters such as PLA or PHB may also be considered "compostable" if they meet with the specifications of international standards (e.g. EN 13432 and ASTM D6400). Therefore, compostability is the characteristic of a biodegradable product that can be successfully biodisintegrated in a particular environment within a specified timeframe and without inducing ecotoxicity. In this regard, not only the biopolymer type and the environment can affect compostability, but the article shape also determines the process. Those articles that have large surface areas and lower thicknesses are easier to degrade. While PLA waste products should be managed in industrial composting plants, those made of PHA can be home, soil or even marine compostable. Industrial composting typically requires biodegradation under aerobic conditions within a timeframe of 6-12 weeks at controlled conditions (e.g. $50-70{ }^{\circ} \mathrm{C}$ and high moisture) ${ }^{87}$. In home composting, temperatures and volumes are significantly lower than those found in industrial composting facilities and conditions are also less stable so that the biodegradation process works slower. In particular, products labeled as "home compostable" habitually need to demonstrate at least $90 \%$ biodegradation within a year at temperatures of below $30{ }^{\circ} \mathrm{C}$ and at least $90 \%$ disintegration within six months. Some PHA products can also degrade in specific open environments. Indeed, scl-PHA-degrading microorganisms of many taxa are widely distributed in various ecosystems such as soil, sewage sludge, compost, and marine water, being more abundant than those for $\mathrm{mcl}$-PHA-degrading ones ${ }^{\mathrm{REF}}$. However, biodegradation in these conditions is impaired and longer due to temperatures, that are habitually low and, in some cases, they lack of bacteria and/or fungi (e.g. oceans).

In addition to composting, other sustainable end-of-life pathways are still possible for articles made of PLA or PHA. These include, for instance, anaerobic digestion, thermal treatment in a waste incineration plant, treatment and use as refuse derived fuel (e.g. in cement kilns) as well as mechanical or chemical recycling 85 . Furthermore, although these are primarily intended for short-life products (e.g. packaging) the reuse or melt-reprocessing of PLA or PHA products is also feasible ${ }^{88,89}$. Indeed, the industrial composting of PLA articles has been identified as the worst option from a climate perspective since it neither improves the quality of compost nor allows for energy recovery ${ }^{90,91}$. Moreover, fixed carbon is predominantly converted into carbon dioxide, increasing the greenhouse gas emissions. 
Apart from energy recovery methods, the mechanical and chemical recycling of PLA- and PHA-containing waste promises to reduce the environmental impact of plastic packaging ${ }^{92-94}$. Figure 6 shows a scheme of the different end-to-life assessments of poly(hydroxy acids), considering its potential recycling. This process has been well reported for PLA and it can be summarized as follows ${ }^{95}$. During chemical recycling, the PLA-containing packaging waste is collected and transported to a sorting plant in which, by means of a near infrared light (NIR)-based sorting procedure, it is first sorted out. In the next steps, the PLA-containing fraction is shredded and further purified. The resultant purified post-consumer waste of PLA can be then depolymerized. Nevertheless, the thermal depolymerization reaction is not straightforward. As investigated by Kopinke et al. ${ }^{96}$, during the depolymerization reaction apart from obtaining lactide with considerable racemization, acrylic acid (AA) depolymerization reaction, Nishida et al. ${ }^{97}$ combined thermal treatment with different catalysts to favor the selective depolymerization into lactide units. It was found that, in the presence of calcium oxide and at temperatures lower than $250{ }^{\circ} \mathrm{C}$, meso-lactide was predominantly formed (>75\%). However, at temperatures in the range of $250-320{ }^{\circ} \mathrm{C}$, the unzipping depolymerization mechanism dominated, resulting in more selective L-lactide formation. Industrially, the commercial production of Llactide monomer is based on the tin catalyzed selective depolymerization of low $M_{w}$ PLLA, which allows Figure 7. Available end-of-life options for poly(hydroxy acids)obtaining production yields of around $80 \%$. While the cyclic depolymerization has already been implemented industrially to obtain cyclic esters, the hydrolytic degradation of PLLA give rise to the hydroxy acid molecules.

The hydrolytic chemical depolymerization of PLLA has been

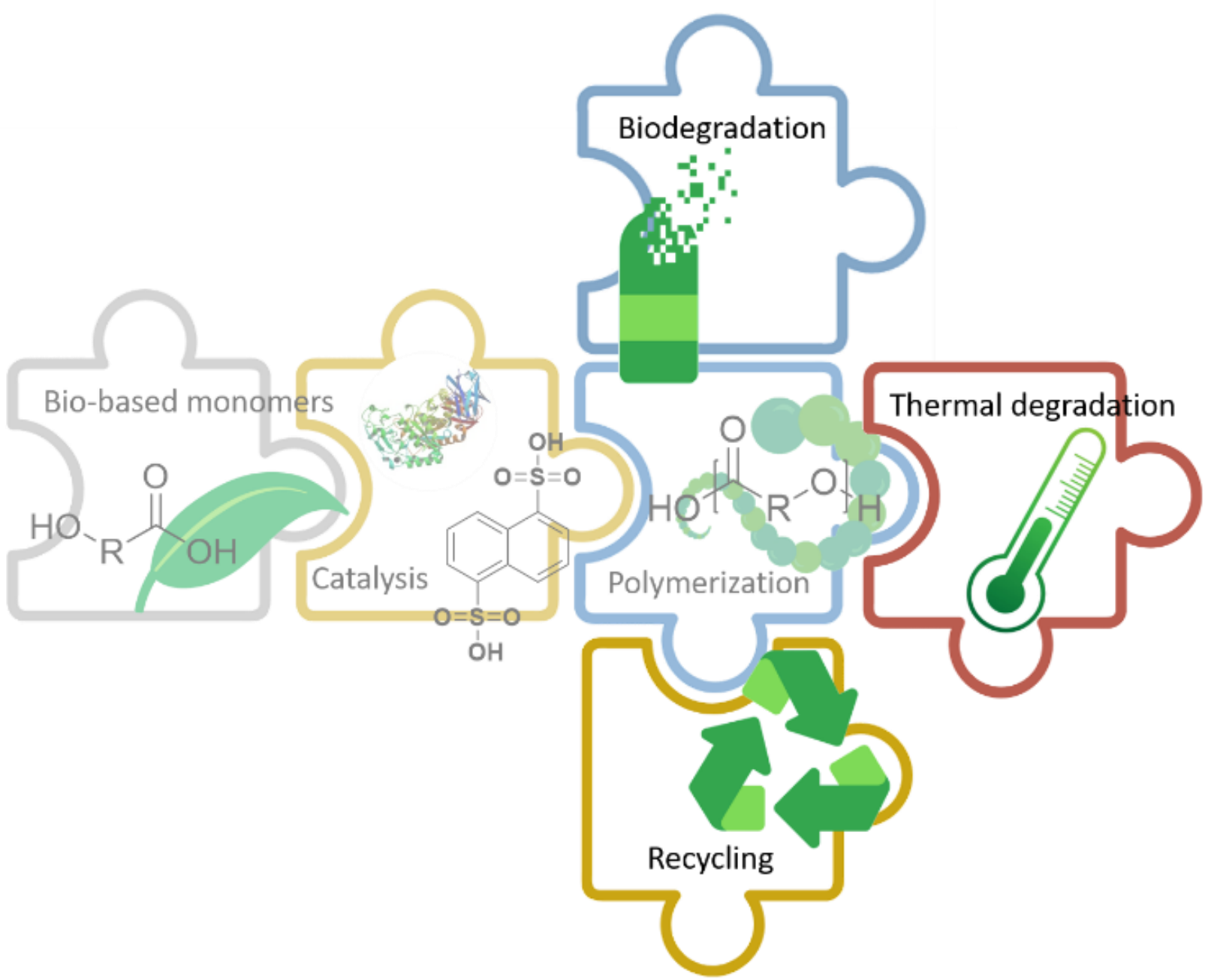

Figure 6. Available end-of-life options for poly(hydroxy acids). from cis-elimination, as well other compounds from fragmentation reactions, were produced. In order to obtain better yields in the studied by many groups in order to obtain lactic acid ${ }^{98}$. The findings of this research suggest that depolymerization efficiency depends on temperature, the water-to-polymer ratio, the 
crystallinity of the polymer, and the $\mathrm{pH}$ of the medium. The higher the temperature, the lower the yield of lactic acid, because temperature induces the creation of other low- $M_{w}$ organic compounds. The cleavage of the ester groups proceeds preferentially in the amorphous phase due to the better water diffusion and lower stability of the polymer ${ }^{99,100}$. The $\mathrm{pH}$ of the medium is also an influencing factor in the depolymerization rate. Lyu ${ }^{101}$ studied this effect using different tetrahydrofuran (THF) solutions from $\mathrm{pH} 0$ to 14. It was determined that $\mathrm{pH} 4$ was the one that yielded the lowest reaction rate due to the similarity with the pKa value of the lactic acid, that is, 3.79. For the cases where the $\mathrm{pH}$ of the medium was above 4, it contained lactic acid at the end of the chain mainly in its dissociated form and it that accelerates the hydrolysis process. In the opposite cases, when $\mathrm{pH}$ was below 4, lactic acid was in its associated acid form, which accelerated the hydrolytic depolymerization via auto-acceleration ${ }^{102}$.

The hydrolytic depolymerization of PHB has also been studied to obtain $3 \mathrm{HB}$ or a cyclic dimer and trimer that could enable repolymerization. Li and Strathmann ${ }^{103}$ showed that for the depolymerization in water media, temperatures above $200{ }^{\circ} \mathrm{C}$ were required. However, the reaction resulted in two products, $3 \mathrm{HB}$ in a larger scale and crotonic acid (CA) in a minor scale. However, this ratio varied by changing the $\mathrm{pH}$ of the media and also the temperature used. In particular, the higher the temperature, the lower the reaction time required to completely depolymerizing PHB. Nevertheless, temperatures above $220{ }^{\circ} \mathrm{C}$ decreased carbon recovery because $3 \mathrm{HB}$ and $\mathrm{CA}$ decompose to give gas products ${ }^{104}$. Furthermore, the Seebach ${ }^{105}$ and Höcker ${ }^{106}$ groups were able to depolymerize poly[(R)-3HB] into cyclic trimer of $3 \mathrm{HB}$ with a yield of $50 \%$. Höcker and coworkers ${ }^{103}$ determined that the catalyzed depolymerization in melt yields linear hydroxy acids with $\omega$ crotonate end groups and CA via ester pyrolysis mechanism at 200$320^{\circ} \mathrm{C}$, independent of the catalyst used. In solution, instead, cyclic oligomers were obtained via backbiting reaction using dibutyltin dimethoxide or p-toluenesulfonic acid as the catalyst.

Depolymerization of two types of PHBV with 3HV contents of 12 mol\% and 19 mol\% was successfully achieved by catalytic pyrolysis using alkali earth compound (AEC) catalysts, such as calcium oxide $\mathrm{CaO}$ and magnesium hydroxide $\left(\mathrm{Mg}(\mathrm{OH})_{2}\right)$, resulting in lower degradation temperatures and selective transformation of the copolyester into vinyl monomers, that is, CA and 2-pentenoic (2-PA) REF6. Moreover, obtained CA from 3-hydroxybutyrate sequences in PHBV was copolymerized with AA to produce useful water-soluble poly(crotonic acid-co-acrylic acid) (PCA-co-AA) copolymers. Liner et al. ${ }^{\mathrm{REF}}$ also reported the thermal depolymerization of a lignin derived mcl-PHA having a hydroxy acid monomer distribution comprising 3hydroxydecanoic acid (55\%), 3-hydroxyoctanoic acid (22\%), 3hydroxydodecanoic acid (16\%), 3-hydroxytetradecancoic acid (4\%), and 3-hydroxyhexanoic acid (3\%) was depolymerized. This process was performed at $250^{\circ} \mathrm{C}$ under inert atmosphere and it resulted in C6-C14 alkenoic acids that further depolymerized and deoxygenated ("depoly-deoxy") into hydroxy acids and hydrocarbons, respectively, using bimetallic platinum-rhenium (Pt-Re) catalyst supported on activated carbon by using water as a solvent.

In order to modify the properties of the recycling pellets, additives and stabilizers can be added in the same way as it is done for commercial poly(hydroxy acids) production. Piemonte et al. ${ }^{107}$ compared the mechanical and chemical recycling of PLA, showing that the later process entails better results in human health, ecosystem quality, and resources categories. Moreover, PLA produced by mechanical recycling presented lower quality, while the PLA chemical recycling process can also be theoretically performed several times due depolymerization produces a monomer that will be used to generate a completely new biopolymer. In any case, chemical recycling technologies are still under development and, due to current technical constraints, nowadays only $10 \%$ of PLA waste is added as replacement of lactic acid to the PLA production process.

\section{Conclusions and outlook}

Biopolyesters derived from hydroxy acids such as PLA and PHB and their copolymers can undoubtedly make a significant impact in the field of sustainable packaging, considering their good performance and that they follow a circular model by design. In addition, some of these biopolyesters can be tuned to be fully biodegradable in certain conditions, which is an interesting advantage in regard other kind of polymers. However, the current method to recover the biopolyester into its monomeric units is still not fully developed and the current approach will require unique catalysts to guide the cyclic depolymerization steps. 
One potential solution to this problem may be found in the hydrolytic depolymerization of polyesters into hydroxy acids, which are monomers that could yield a more feasible Circular Economy's solution. Moreover, hydroxy acids are widely found in nature and they can potentially replace petrochemical monomers and their polymers. Another interesting feature of hydroxy acids is that they have, at least, one nucleophile (alcohol group) and one electrophile (carboxylic acid group) in the monomeric structure, allowing its selfcondensation that enables to maintain the stoichiometry to facilitate the achievement of high- $\mathrm{M}_{\mathrm{w}}$ polymers.

Nonetheless, beyond all the efforts highlighted, a significant progress still has to be made in the area of polyesters derived from hydroxy acids to make their synthesis a competitive process in comparison to ROP or conventional step-growth polymerization. Among them, the most important remaining challenges include: 1) The rise of the $M_{w}$ values, which are still low compared with ROP routes or also with metal catalyzed conventional step-growth polymerization; 2) The use of organocatalysts, which will enable their elimination from the reaction media to make the final product suitable for electronics or even biomedical applications; 3 ) The need to find a more cost-effective catalyst since most of the organocatalysts used are expensive organic molecules, making their current implementation in the industry economically unviable; 4) The reduction of the catalyst loading, which are much superior to the organometallic catalyst, even though these organocatalysts are easy to remove from the polymer by precipitation/extraction.

Considering the challenges described above, a number of innovations are still needed to make the transition of biopolyesters derived from hydroxy acids from the laboratory to the industry. From our perspective, the reactor that is used for conventional stepgrowth polymerization should be adequate also for this polymerization. In particular, it is highly important that the vacuum employed would be high enough and it also comprises a strong mechanical stirring in order to efficiently remove the water from the reaction media, which will trigger the growth of the polyester's $\mathrm{M}_{\mathrm{w}}$. Moreover, the implementation of SSP or the use of solvents with low toxicity and high boiling point can also enhance water removal, allowing the preparation of biopolyesters with adequate $M_{W}$ values for industrial implementation ${ }^{108}$.

Considering the biodegradability and recycling properties of these polyesters derived from hydroxy acids, it is thought that their application field will be extended in the following years. This is based on the evident benefits that they can show compared with the conventional polymerization routes.

\section{Conflicts of interest}

The authors declare not conflict of interest.

\section{Acknowledgements}

The authors thank the European Commission (EC) for financial support through the project SUSPOL-EJDH2020-ITN-2014-642671 and the Spanish Ministry of Science and Innovation (MICI) through the projects RTI2018-097249-B-C21, MAT2017-83373-R, and MAT2016-78527-P. S. Torres-Giner also acknowledges MICI for his Juan de la Cierva-Incorporación contract (IJCl-2016-29675) and the financial support received during his stay at the Institute for Polymer Materials (POLYMAT).

\section{References}

\author{
P. J. Flory, Principles of Polymer Chemistry, Cornell \\ University Press, 1995.
}

PlasticsEurope, Plast. - Facts 2018, 2018, 38.

Fiber Year 2018 World Surv. Text. nonwovens, Fiber Year Consult.

M. Hong and E. Y. X. Chen, Green Chem., 2017, 19, 36923706.

C. Jehanno, M. M. Pérez-Madrigal, J. Demarteau, H. Sardon and A. P. Dove, Polym. Chem., 2019, 10, 172-186.

H. Charles, J. Godfray, J. R. Beddington, I. R. Crute, L. Haddad, D. Lawrence, J. F. Muir, J. Pretty, S. Robinson, S. M. Thomas and C. Toulmin, Science (80-. )., 2010, 327, 812. Growing at a slower pace, world population is expected to reach 9.7 billion in 2050 and could peak at nearly 11 billion around 2100 | UN DESA | United Nations Department of Economic and Social Affairs.

R. A. Gross and B. Kalra, Science (80-. )., 2002, 297, 803807. 
9 Food Sci. Technol., 2008, 19, 634-643.

G. Odian, principles of polymerization, John Willey \& Sons, Inc New Jersey, 4th editio., 2004.

S. R. . Rogers, M.E.; Long, T.E.; Turner, Introduction to synthetic methods in step-growth polymers, John Willey \& Sons, New Jersey, 2003.

R. Löfgren, A., Albertsson, A.C., Dubois, P. Jerome, J. Macromol. Sci., 1995, C35, 379-418.

I. K. . Albertson, A.C.; Varma, Aliphatic polyesters: Synthesis, properties and applications in Degradable aliphatic polyesters, A.C. Berlin, Springer-Verlag, Albertson., 2001. 218.

A. Bossion, K. V. Heifferon, L. Meabe, N. Zivic, D. Taton, J. L. Hedrick, T. E. Long and H. Sardon, Prog. Polym. Sci., 2019, 90, 164-210.

T. C. Bhalla, V. Kumar and S. K. Bhatia, 2011, 56-76.

H. Fukuzaki, M. Yoshida, M. Asano, M. Kumakura, T. Mashimo, H. Yuasa, K. Imai and H. Yamanaka, Biomaterials, 1991, 12, 433-437.

A. Sangroniz, J. B. Zhu, X. Tang, A. Etxeberria, E. Y. X. Chen and H. Sardon, Nat. Commun., 2019, 10, 3559.

S. T. Kenny, J. N. Runic, W. Kaminsky, T. Woods, R. P. Babu and K. E. O'Connor, Appl. Microbiol. Biotechnol., 2012, 95, 623-633.
M. Ajioka, K. Enomoto, K. Suzuki and A. Yamaguchi, Bull. Chem. Soc. Jpn., 1995, 68, 2125-2131.

A. K. Santosh K. Gupta, Reaction Engineering of Step Growth Polymerization, Springer Science \& Business Media, 2012.

S. D. S. and N. Shetty, Mater. Res. Express.

Y. Hu, W. A. Daoud, K. K. L. Cheuk and C. S. K. Lin, Materials (Basel)., 2016, 9.

H. Korhonen, A. Helminen and J. V. Seppälä, Polymer (Guildf)., 2001, 42, 7541-7549.

Kittawat Poonsawat and Manus Seadan, Determination of Molecular Weight and Molecular Weight Distribution of Poly(lactic acid) by Dynamic Mechanical Properties of Polymer in Melted State., .

D. Lascano, G. Moraga, J. Ivorra-Martinez, S. Rojas-Lema, S. Torres-Giner, R. Balart, T. Boronat and L. Quiles-Carrillo, Polymers (Basel)., , DOI:10.3390/polym11122099.

T. Yamamoto, Y. Hayashi and A. Yamamoto, Bull. Chem. Soc. Jpn., 1978, 51, 2091-2097.

S. II Moon, C. W. Lee, M. Miyamoto and Y. Kimura, J. Polym. Sci. Part A Polym. Chem., 2000, 38, 1673-1679.

Z. Lei, Y. Bai and S. Wang, Chinese Sci. Bull., 2005, 50, 2390-2392.

H. Auras, R.; Lim, L.T.; Selke, S.E.M.; Tsuji, Poly (Lactic Acid): Synthesis, Structures, Properties, Processing, and Applications, NJ, USA, John Wiley., 2010.

K. Takahashi, I. Taniguchi, M. Miyamoto and Y. Kimura, Polymer (Guildf)., 2000, 41, 8725-8728.

A. Takasu, Y. Narukawa and T. Hirabayashi, J. Polym. Sci. Part A Polym. Chem., 2006, 44, 5247-5253.

B. Peng, Y. Xu, J. Hu, Z. Bu, L. Wu and B. G. Li, Polym. Degrad. Stab., 2013, 98, 1784-1789.

A. Mahapatro, A. Kumar and R. A. Gross, 
Biomacromolecules, 2004, 5, 62-68.

J. Lunt, Polym. Degrad. Stab., 1998, 59, 145-152.

40

S. Chuensangjun, C., Pechyen, C., Chisti, Y., Sirisansaneeyakul, Adv. Mater. Res., 2012, 506, 154-157.

Q. L. Zhou, Angew. Chemie - Int. Ed., 2016, 55, 5352-5353.

H. Sardon, A. Pascual, D. Mecerreyes, D. Taton, H. Cramail and J. L. Hedrick, Macromolecules, 2015, 48, 3153-3165.

I. Flores, A. Basterretxea, A. Etxeberria, A. González, C. Ocando, J. F. Vega, J. Martínez-Salazar, H. Sardon and A. J. Müller, Macromolecules, 2019, 52, 6834-6848.

A. Basterretxea, E. Gabirondo, C. Jehanno, H. Zhu, I. Flores, A. J. Müller, A. Etxeberria, D. Mecerreyes, O. Coulembier and H. Sardon, ACS Sustain. Chem. Eng., 2019, 7, 41034111.

L. Meabe, H. Sardon and D. Mecerreyes, Eur. Polym. J., 2017, 95, 737-745.

C. Jehanno, I. Flores, A. P. Dove, A. J. Müller, F. Ruipérez and H. Sardon, Green Chem., 2018, 20, 1205-1212.

Y. Bai and Z. Lei, Polym. Int., 2007, 56, 1261-1264.

E. M. Filachione and C. H. Fisher, Ind. Eng. Chem., 1944, 36, 223-228.

P. D. Watson, Ind. Eng. Chem., 1948, 40, 1393-1397.

S. II Moon, H. Urayama and Y. Kimura, Macromol. Biosci., 2003, 3, 301-309.

P. Penco, M., Ranucci, E., and Ferruti, Polym. Int., 1998, 46, 203-216.

L. L. Hench, J. R. Jones and M. Institute of Materials, Biomaterials, artificial organs and tissue engineering, CRC Press, 2005.
Y. Wang, R. Chen, J. Y. Cai, Z. Liu, Y. Zheng, H. Wang, Q. Li and N. He, PLoS One.

\section{S. Torres-Giner, N. Montanes, T. Boronat, L. Quiles-Carrillo} and R. Balart, Eur. Polym. J., 2016, 84, 693-707.

J. Liggat, Polym. Int., 1996, 39, 167-167.

M. Kunioka, A. Tamaki and Y. Doi, Macromolecules, 1989, 22, 694-697.

\section{S. Philip, T. Keshavarz and I. Roy, J. Chem. Technol.} Biotechnol., 2007, 82, 233-247.

S. Tomizawa, M. Yoshioka, K. Ushimaru and T. Tsuge, Polym. J., 2012, 44, 982-985.

B. H. A. Rehm, Biochem. J., 2003, 376, 15-33.

M. Pötter and A. Steinbüchel, Biomacromolecules, 2005, 6, 552-560.

Z. Jedliński, P. Kurcok and R. W. Lenz, Macromolecules, 1998, 31, 6718-6720.

T. Moore, R. Adhikari and P. Gunatillake, Biomaterials, 2005, 26, 3771-3782.

X. Tang and E. Y. X. Chen, Nat. Commun., 2018, 9, 2345.

X. Tang, A. H. Westlie, E. M. Watson and E. Y. X. Chen, Science (80-. )., 2019, 366, 754-758.

D. O'Hagan and N. A. Zaidi, J. Chem. Soc. Perkin Trans. 1, 1993, 2389-2390.

X. Shuai, Z. Jedlinski, M. Kowalczuk, J. Rydz and H. Tan, Eur. Polym. J., 1999, 35, 721-725.

R. Croteau and P. E. Kolattukudy, Biochemistry, 1974, 13, 3193-3202.

T. H. Thi, M. Matsusaki, D. Shi, T. Kaneko and M. Akashi, J. Biomater. Sci. Polym. Ed., 2008, 19, 75-85.

J. F. J. C. and A. C. S. A. C. Fonseca, M. S. Lima, A. F. Sousa, A. J. Silvestre, Polym.Chem., 2019, 10, 1696-1723. 


\section{Polymer Chemistry}

72

M. Matsusaki, A. Kishida, N. Stainton, C. W. G. Ansell and M. Akashi, J. Appl. Polym. Sci., 2001, 82, 2357-2364.

M. Matsusaki, H. T. Tran, T. Kaneko and M. Akashi, Biomaterials, 2005, 26, 6263-6270.

H. R. Kricheldorf and G. Löhden, Polymer (Guildf)., 1995, 36, 1697-1705.

D. Teomim, A. Nyska and A. J. Domb, J. Biomed. Mater. Res., 1999, 45, 258-267.

X. Zou, C. Cheng, J. Feng, X. Song, M. Lin and S. T. Yang, Crit. Rev. Biotechnol., 2019, 39, 408-421.

S. K. Ghosh, S. Pal and S. Ray, Environ. Sci. Pollut. Res. Int., 2013, 20, 4339-4355. A. A. Shah, F. Hasan, A. Hameed and S. Ahmed, Biotechnol. Adv., 2008, 26, 246-265.

T. Ahmed, M. Shahid, F. Azeem, I. Rasul, A. A. Shah, M. Noman, A. Hameed, N. Manzoor, I. Manzoor and S. Muhammad, Environ. Sci. Pollut. Res., 2018, 25, 72877298.

V. Rossi, N. Cleeve-Edwards, L. Lundquist, U. Schenker, C. Dubois, S. Humbert and O. Jolliet, J. Clean. Prod., 2015, 86, 132-145.

R. Shogren, D. Wood, W. Orts and G. Glenn, Sustain. Prod. Consum., 2019, 19, 194-215.
M. K. Hermann, B.G., Debeer, L., De Wilde, B., Blok, K., Patel, Polym. Degrad. Stab., 2011, 1159-1171.

S. Montava-Jorda, D. Lascano, L. Quiles-Carrillo, N. Montanes, T. Boronat, A. V. Martinez-Sanz, S. FerrandizBou and S. Torres-Giner, Polymers (Basel)., 2020, 12, 174

A. Agüero, M. del C. Morcillo, L. Quiles-Carrillo, R. Balart, T. Boronat, D. Lascano, S. Torres-Giner and O. Fenollar, Polymers (Basel)., 2019, 11, 1908.

I. Heidelberg, 2006, 168.

S. Papong, P. Malakul, R. Trungkavashirakun, P. Wenunun, T. Chom-In, M. Nithitanakul and E. Sarobol, J. Clean. Prod., 2014, 65, 539-550.

M. F. Cosate de Andrade, P. M. S. Souza, O. Cavalett and A. R. Morales, J. Polym. Environ., 2016, 24, 372-384.

J. Payne, P. McKeown and M. D. Jones, Polym. Degrad. Stab., 2019, 165, 170-181.

M. Niaounakis, Eur. Polym. J., 2019, 114, 464-475.

D. Maga, M. Hiebel and N. Thonemann, Resour. Conserv. Recycl., 2019, 149, 86-96.

F. D. Kopinke, M. Remmler, K. Mackenzie, M. Möder and O. Wachsen, Polym. Degrad. Stab., 1996, 53, 329-342.

Y. Fan, H. Nishida, T. Mori, Y. Shirai and T. Endo, Polymer (Guildf)., 2004, 45, 1197-1205.

T. Saeki, T. Tsukegi, H. Tsuji, H. Daimon and K. Fujie, Kobunshi Ronbunshu, 2004, 61, 561-566.

M. Hakkarainen, Adv. Polym. Sci., 2002, 157, 113-138.

K. Ginjupalli, G. V. Shavi, R. K. Averineni, M. Bhat, N. Udupa and P. Nagaraja Upadhya, Polym. Degrad. Stab., 2017, 144, $520-535$.

A. M. Eyal and R. Canari, Ind. Eng. Chem. Res., 1995, 34, 1789-1798.

S. Lyu and D. Untereker, Int. J. Mol. Sci., 2009, 10, 4033- 
Review

4065.

103 X. Tang and E. Y. X. Chen, Chem, 2019, 5, 284-312.

104 Y. Li and T. J. Strathmann, Green Chem., 2019, 21, 55865597.

105 D. Seebach, H.-M. Müller, H. M. Bürger and D. A. Plattner, Angew. Chemie Int. Ed. English, 1992, 31, 434-435.

106 M. Melchiors, H. Keul and H. Höcker, Macromolecules, 1996, 29, 6442-6451.

107 V. Piemonte, S. Sabatini and F. Gironi, J. Polym. Environ., 2013, 21, 640-647.

108 D. Bandelli, J. Alex, C. Weber and U. S. Schubert, Macromol. Rapid Commun., 2020, 41, 1900560. 